\title{
Autoria e retórica em produções escritas na escola
}

Quanto mais pudermos escrever para além dos limites de prescrições burocráticas opressoras, tanto mais obteremos o poder de nos definir e representar no mundo letrado Charles Bazerman

\section{Elioenai dos Santos Piovezan ${ }^{1}$ Roberta de Souza Piovezan ${ }^{2}$}

\section{Para iniciar uma conversa inacabada}

autoria de textos escolares por muito tempo foi considerada como
dades de Língua Portuguesa para se verificar a competência escritora
e a gramática do aluno. Como produto de um sujeito em formação, o
texto do aluno geralmente é tratado como cópia de modelos que lhes
são apresentados desde os primeiros anos escolares. Isso não deixa de
ser verdade. No entanto, o processo de escrita, quando realizado com as
condições adequadas que possibilitem ao aluno momentos de reflexão,
troca de ideias e revisão, pode produzir resultados mais positivos do que

1 Doutorando em Língua Portuguesa pela PUC-SP; Mestre em Língua Portuguesa pela PUC-SP; Especialista em Língua Portuguesa pela Unicamp; Membro do Grupo ERA; Bolsista CAPES.

2 Doutoranda em Língua Portuguesa pela PUC-SP; Mestre em Língua Portuguesa pela PUC-SP; Membro do Grupo ERA; Bolsista CAPES. 
a fórmula tradicional da escrita sem propósito ou descontextualizada, visando mais a forma e a correção gramatical do que o conteúdo e a eficácia do ato discursivo do aluno.

Nesse sentido, o exercício de autoria de textos escolares pressupõe uma reflexão que se inicia pelo propósito de escrita e passa inevitavelmente pelo sistema retórico aristotélico. Esse sistema, juntamente com outras categorias, possibilita não apenas a produção de discursos que busquem a eficácia na comunicação, mas também dá condições para que o professor verifique a competência escritora do seu aluno. O sistema retórico, de alguma forma presente nas redações dos alunos, é constituído, segundo os gregos, de quatro partes: inventio, dispositio, elocutio e actio.

A inventio, ou invenção, segundo Mosca (2004), "é o estoque de material, de onde se tiram os argumentos, as provas e outros meios de persuasão relativos ao tema do discurso" (MOSCA, 2004, p. 28), é a busca de argumentos nos lugares retóricos que, de acordo com Ferreira (2010), "são grandes armazéns de argumentos, utilizados para estabelecer acordos com o auditório", mas sempre com o objetivo de persuadir (FERREIRA, 2010, p. 69). Dessa forma, pode-se afirmar que a invenção representa parte estratégica do conteúdo, do que dizer e para quem dizer. A dispositio, ou disposição, para Tringali (2014), é uma arte de organizar em que "o orador constrói seu discurso como um arquiteto constrói um edifício" (TRINGALI, 2014, p. 158). É, portanto, a organização do conteúdo, o modo de dizer aquilo que se pretende dizer. A elocutio, ou elocução, é o "estilo ou as escolhas que podem ser feitas no plano da expressão para que haja adequação forma/ conteúdo" (MOSCA, 2004, p. 28-9). Trata-se da "redação do discurso" (REBOUL, 2004, p. 61). E a actio, a ação, "é a ação que atualiza o discurso, a sua execução" (MOSCA, 2004, p. 29) ou "o arremate do trabalho retórico, a proferição do discurso" (REBOUL, 2004, p. 67).

Transportadas para os tempos atuais de uma sociedade preocupada com o letramento, tanto a invenção como a disposição, a elocução e a ação podem funcionar bem como estratégias de escrita, a pensar nas etapas que a compõem, como ações antecedentes, concomitantes e posteriores à produção de um texto. Tais estratégias permitem que o aluno desenvolva um repertório, esquematize sua escrita e tenha uma visão panorâmica do processo de feitura e recepção de seu texto. Assume, finalmente, a função de autor.

De outro modo, a invenção propicia ao aluno momentos de reflexão, de consulta a fontes de informação, coleção de dados, formação de repertório, troca de ideias com os colegas e contribui, enfim, para o amadurecimento 
sobre o tema. A disposição pressupõe o arranjo estrutural, para a arquitetura do texto, para que as escolhas do que dizer possam ser utilizadas na produção textual de forma adequada ao propósito discursivo. A elocução é a atuação sobre o material obtido na disposição, a fim de que a macroestrutura textual, construída pela disposição, revele a superfície textual, como significação global do ato retórico, e chegue ao auditório, o leitor (FERREIRA, 2010, p. 116).

Outro aspecto que abordaremos mais adiante é a pertinência do trabalho com a escrita a considerar a contribuição da sociorretórica, preconizada por Charles Bazerman (2015). Dessa forma, conceitos como kairós, fatos sociais, atos de fala, significação da forma e paisagem, podem contribuir para preencher possíveis lacunas deixadas pelos gregos que dedicaram boa parte de suas vidas para sistematizar a fala e a escrita e formarem cidadãos capazes de intervir, com eficácia, na vida social e política de seu país.

Afinal, conforme Aristóteles (2013),

seria absurdo afirmar que alguém deve envergonhar-se por ser incapaz de defender-se com seus membros físicos, mas não de ser incapaz de defender-se mediante o discurso racional quando o uso do discurso racional distingue mais o ser humano do que o uso de seus membros. (ARISTÓTELES, 2013, I, p. 43).

Logo, desenvolver a capacidade escritora do aluno, por meio do exercício de autoria, é uma tarefa inestimável para o professor diante das exigências e desafios do mundo contemporâneo. Para tanto, apresentamos a seguir um breve panorama sobre a retórica aristotélica, a sociorretórica de Bazerman (2015) e indícios de autoria. Por fim, a partir dessas contribuições teóricas, analisamos uma carta argumentativa produzida por uma aluna de $6^{\circ}$ ano do Ensino Fundamental II.

\section{Da retórica antiga aos gêneros textuais}

Assim como a escrita, a retórica surgiu da necessidade humana de resolver problemas do cotidiano. De acordo com Ferreira (2010), o primeiro tratado de retórica foi escrito em 465 a.C. por Córax e seu discípulo Tísias, dois notáveis oradores que defendiam as vítimas de Trasíbulo, tirano de Siracusa que havia tomado as terras de muitos cidadãos. Em um ambiente de 
contendas jurídicas, os cidadãos pleiteavam, com uso de oratória e retórica, a devolução de suas terras. Lançavam-se dessa forma as bases da retórica, que nascia amparada por uma "oratória caracteristicamente probatória, que buscava provas (pisteis)" e também "assumia o aspecto técnico de uma arte com preceitos assentados cientificamente e tinha por objetivo demonstrar a verossimilhança de uma tese proposta" (FERREIRA, 2010, p. 41).

A retórica possuía, então nos tempos de Sócrates, Platão e Aristóteles e sob as condições de uma sociedade democrática, um valor social inquestionável. Coube a Aristóteles, entretanto, sistematizar a força dos atos discursivos, da oratória, em um sistema retórico que permitisse a qualquer pessoa elaborar discursos eficazes para um propósito determinado.

Segundo Ferreira (2010), a obra "Arte Retórica” (s/d), escrita por Aristóteles, legou à humanidade um "verdadeiro guia sobre como criar um texto persuasivo e trouxe ensinamentos, muito válidos até hoje, sobre elementos da gramática, de Filosofia, Filosofia da Linguagem, Lógica e Estilística" (FERREIRA, 2010, 43-4). Desde então, a retórica esteve presente em maior ou menor grau tanto nos debates políticos como nos currículos escolares. Aperfeiçoado por Cícero (século II a.C.), que "demonstrou aos romanos a força e a beleza da palavra" (FERREIRA, 2010, p. 44), e Quintiliano (século I-II d.C.), que estabeleceu "a pedagogia da retórica aristotélica” (FERREIRA, 2010, p. 44), a retórica entrou em decadência após o fim do período republicano, uma vez que sob governos autoritários não há espaço para o debate de ideias.

Dessa forma, a retórica ficou, por séculos, relegada à artificialidade da palavra em situações mais fictícias do que reais e viu "diminuir sua carga efetiva de ação" (FERREIRA, 2010, p. 45). Após o fim da Idade Média e até o século XX, a retórica enfrentaria "adversários poderosos", como

o Positivismo, que rejeitou a retórica por só acreditar na verdade científica; depois o Romantismo, que rejeitou a retórica, pois queria enaltecer a sinceridade a toda prova. Em 1895, a retórica despareceu do ensino francês e foi substituída pela História das literaturas grega, latina e francesa. (FERREIRA, 2010, p. 45).

Mas foi somente com os novos retóricos, a partir da segunda metade do século XX, que a retórica, renovada e adaptada aos novos tempos do mundo midiatizado, conseguiu restabelecer seu status de arte e ciência do discurso. De forma bem simples, a Nova Retórica e diferentes teóricos que a representam, como Perelman e Olbrechts-Tyteca, Meyer, Reboul, Grize,

Dubois, entre outros, 
acentuam que é no mundo da opinião que se tecem as relações entre os homens e é a retórica do verossímil que permite o espaço persuasivo para a inserção do não racional no domínio retórico. Abre-se, pois, espaço para o sentimento, para o universo passional e sua força retórica. (FERREIRA, 2010, p. 47).

Paralelamente ao ressurgimento da retórica e a se considerar a importância da produção de discursos como forma de interação social, temos a partir das contribuições de Bakhtin e seu Círculo uma verdadeira revolução nas relações entre linguagem e sociedade. O filósofo russo, "descoberto" apenas na década de 1970 pelos linguistas, apresenta os gêneros do discurso como concretização da ação comunicativa humana e estabelece as condições para a abordagem de enunciados que, por serem relativamente estáveis, podem ser reconhecidos, agrupados e estudados.

Assim, os gêneros discursivos também compreendidos como gêneros textuais, por sua propriedade e consistência, foram adaptados para o ensino de língua materna de vários países. Pesquisadores como Dolz e Schnewuly (2004) organizaram os gêneros, a partir de seus aspectos tipológicos e capacidades de linguagens globais, em cinco agrupamentos: narrar, relatar, expor, argumentar e descrever ações. Esses agrupamentos de gêneros permeiam todo o currículo de Língua Portuguesa dos sistemas de ensino brasileiro, em uma espiral progressiva de retomadas e aprofundamentos de conteúdos.

Ressaltamos que, na perspectiva bakhtiniana, o gênero sempre é mediado por relações de interação social, pois

a língua materna - a composição de seu léxico e sua estrutura gramatical -, não a aprendemos nos dicionários e nas gramáticas, nós a adquirimos mediante enunciados concretos que ouvimos e reproduzimos durante a comunicação verbal viva que se efetua com os indivíduos que nos rodeiam. (BAKHTIN, 1997, p. 301).

Logo, como a fala é moldada nas formas do gênero, o interlocutor reconhece ou prevê de imediato tal gênero, considerada sua estrutura composicional. Na escola, o aluno, após algum contato com determinado gênero, passa a reconhecê-lo em outras ocasiões, obviamente respeitando-se o grau de complexidade desses enunciados. Assim, nos $6^{\circ}$ e $7^{\circ}$ anos do Ensino Fundamental II, os textos selecionados geralmente são curtos e apresentam baixa complexidade em sua estrutura textual e discursiva, como fábulas, contos de fada, crônicas literárias, memórias literárias, tiras, 
cartas de leitor, cartas argumentativas, artigos de divulgação científica (para crianças), notícias, poemas, entre outros. Enfim, o trabalho com gêneros textuais coloca o aluno em contato com a língua materna em suas diferentes manifestações e lhe propicia uma aprendizagem significativa, desde que haja propósitos de leitura e escrita.

\section{Kairós, fatos sociais, atos da fala e propósito de escrita}

Os propósitos de escrita estão relacionados ao que Bazerman (2015) chama de kairós, o momento oportuno, que para os gregos são "esses amplos movimentos da história", cuja função é "levar à contemplação consciente esse sentido do momento certo", ou ainda, que "nos ajuda a considerar a posição temporal, momentos que se agrupam e se desfazem, oportunidades passageiras que podemos perceber e utilizar, com vistas a modificar o curso dos eventos por meio de nossa intervenção oportuna" (BAZERMAN, 2015, p. 58-9).

Dessa forma, podemos inferir que o propósito da escrita surge com o tempo kairós, pois um motivo para escrever "corporifica um desejo ou necessidade de modificar a situação" (BAZERMAN, 2015, p. 85). Nesse sentido, a situação ou questão retórica "é uma situação exigente marcada por uma imperfeição que pode ser corrigida pela linguagem" (BITZER, 1968, apud BAZERMAN, 2015, p. 85). Por isso, cabe a cada indivíduo perceber o momento oportuno para intervir no meio social. Em uma situação de aula, o aluno é convidado a escrever a partir de um problema hipotético e com a apresentação de um repertório básico de informações.

Sabemos que o multiletramento do mundo contemporâneo exige cada vez mais das pessoas o uso de capacidades leitora e escritora para realizar tarefas cotidianas e compartilhar seus conhecimentos ou posicionamentos. De fato, a partir de problemas ou necessidades que surgem cotidianamente, "uma situação só vem à consciência e toma forma a partir da percepção de uma exigência" (BAZERMAN, 2015, p. 85). As pessoas só se mobilizam pela linguagem quando o assunto é de interesse para suas vidas.

Se todo discurso é um ato retórico, pois pressupõe uma ação responsiva do leitor, e se somos "seres retóricos" (FERREIRA, 2010), logo, "influenciar seres humanos por meio da linguagem é igualmente uma questão de avaliação, seleção de campos de ação e adaptação a condições existentes, mesmo na tentativa de transformá-las" (BAZERMAN, 2015, p. 87). É possível consi- 
derar aqui o contexto retórico, em que Bazerman (2015) expande o alcance do discurso ao afirmar que

os fatos sociais são condicionados pelas condições materiais e pelas experiências disponíveis para as pessoas, e responsáveis perante elas, mas, em última análise, o mundo simbólico da comunicação deve falar à consciência e ao componente emocional de nossos públicos. Nossas afirmativas devem tornar-se fatos para eles, parte da paisagem simbólica na qual vivem. (BAZERMAN, 2015, p. 88).

Disso, o autor conclui que "atos de fala criam fatos sociais que alteram o modo como as pessoas veem suas paisagens interiores e exteriores, as relações com aqueles que as cercam, suas condições materiais e a si mesmas" (BAZERMAN, 2015, p. 88). Assim, podem resultar atos responsivos, desde uma neutralidade emocional diante de uma conta de luz até uma perturbação que altere a consideração sobre pessoas e seus comportamentos moralmente questionáveis. Afinal, "atos de fala devem tornar-se fatos sociais ao serem bem-sucedidos" (BAZERMAN, 2015, p. 88).

De qualquer forma, "a ligação entre situação retórica, ato de fala, fato social e gênero pode colaborar para uma ação efetiva” (BAZERMAN, 2015, p. 90), pois dada a estabilidade do gênero, o autor de um texto tem melhores condições de adequar seu discurso a uma determinada situação. Porém, "as condições da escrita costumam estar apartadas do ambiente imediato, com o escritor e o leitor não visíveis um ao outro e separados no tempo" (BAZERMAN, 2015, p. 93). Logo, na sala de aula é necessário que se faça um exercício de imaginação para se considerar o interlocutor ideal a quem será direcionado o discurso, pois o propósito da escrita é modificar a paisagem e, por meio do ato de fala, criar um fato social.

\section{Autoria e sistema retórico}

A considerar que a sociedade atual precisa de cidadãos letrados (ou multiletrados), sabemos que essa tarefa é realizada primordialmente pela escolarização, que tem focado, desde a educação infantil, as práticas de linguagem como a oralidade, a interpretação, a escrita e os estudos dos fatos linguísticos (BRASIL, 2017). Diante disso, é fácil concordar com Bazerman, quando afirma que 
a escrita pode ser um potente instrumento de pensamento, sentimento, identidade, engajamento e ação. Ao transformar nossos impulsos em palavras, podemos revelar-nos a nós mesmos e ao mundo, podemos participar de importantes debates, movimentos e atividades. (BAZERMAN, 2015, p. 8).

Portanto, o trabalho com autoria na escola pressupõe que o aluno produza significações, pois "escrever, como em toda a linguagem, é um veículo para evocar significações na mente de outras pessoas" (BAZERMAN, 2015, p. 130). Podemos afirmar, então, que é a partir da invenção (do sistema retórico) que o aluno começa a exercitar sua função de autor, passa a refletir sobre o tema e as instruções apresentadas pelo professor, reúne as informações disponíveis (disposição) e pensa na melhor forma de persuadir seu leitor com o discurso pronto (elocução) e publicado (ação).

Esse exercício permite que a questão retórica seja contextualizada, em princípio, mentalmente e depois em forma de anotações, registros ou esquemas. Pensar na recepção do texto, na perspectiva do outro, é uma boa oportunidade de exercitar a capacidade de alteridade. De qualquer modo, é ponto pacífico que a ausência de textos mobilizadores, de discussão prévia e de tempo para pesquisar e refletir sobre o tema apresentado dificulta ou mesmo inviabiliza a produção de textos que contenham "indícios de autoria" (POSSENTI, 2002).

Nesse sentido, entendemos que uma proposta de redação que considere as condições de escrita e contextualize a situação retórica contribui para o aluno exercer autoria. Entretanto, para verificarmos a constituição efetiva da presença do autor, é preciso atentar-se para algumas categorias que contribuem com essa tarefa. Dessa forma, com base na retórica antiga e nas contribuições do Círculo bakhtiniano, Piovezan (2017) sugere o trabalho com seis categorias de análise: unidade de sentido, marca de posição de autor, autoconsciência de linguagem, polifonia, qualidade e criatividade.

A unidade de sentido é garantida pela coesão e coerência textuais, que juntas representam a concatenação, a indissociabilidade entre macroestrutura e microestrutura do texto, em que o autor já consegue contemplar sua criação.

A marca de posição de autor pode ser verificada pela modalização do dizer, que envolve o uso de dêiticos (pronomes pessoais, advérbios de lugar) e revelam a presença com distância maior ou menor do orador em relação ao seu auditório.

A autoconsciência de linguagem é percebida pela presença de fatos buscados no mundo real que, conforme Bakhtin (1997), refletem e refratam a realidade vivida e compreendida pelo autor. 
A polifonia, conceito desenvolvido por Bakhtin (1997), considera os diversos agrupamentos de gêneros textuais e discursivos (e não apenas os narrativos), pode ser constatada pela presença, intencional ou involuntária, de outras vozes, como citações diretas ou indiretas, aforismos, lugares-comuns (com ampliação ou subversão do sentido de clichês ou chavões).

A qualidade envolve a capacidade de utilizar os recursos textuais e discursivos, que atendam minimamente à forma composicional do gênero e que consigam coadunar com elegância, equilíbrio e responsabilidade o conteúdo proposto pelo professor. Percebemos a qualidade de um texto pelo uso de conectivos, referenciação, concordância, pontuação e outros recursos que dão ao texto fluidez e não o tornam prolixo.

A criatividade pode ser verificada no estilo de linguagem adotado pelo autor. No Ensino Fundamental, é muito provável que o aluno não apresente autonomia criativa em suas produções. A tendência é que siga modelos, que tenha contato com textos canônicos quando se tratar da literatura ou com textos técnico-profissionais quando se tratar de gêneros midiáticos, expositivos ou prescritivos. É um momento de descobertas de possibilidades textuais e discursivas. Somente com a prática de leitura e escrita é que o aluno-autor poderá desenvolver um estilo de linguagem e expressar maior criatividade.

Todos esses elementos também são observáveis na disposição do texto, ou seja, na organização do discurso, pois é a partir da arquitetura textual (disposição) que o aluno utiliza estratégias de dizer, com argumentos, explicações e exemplos, para convencer, comover ou persuadir o leitor (elocução). Dessa forma, acreditamos que a eficácia discursiva seja resultado da capacidade textual e discursiva do aluno que, ainda com limitações de conhecimentos linguísticos, sabe que precisa produzir uma escrita com responsabilidade, coesão e coerência (ação). Logo, o sistema retórico reflete a capacidade organizacional do texto do aluno e revela sua autoria que, nessa fase da vida e no âmbito da escola, está em pleno desenvolvimento.

\section{Um olhar retórico sobre a carta argumentativa}

Após uma breve passagem por algumas teorias do texto e do discurso, buscamos agora identificar a presença de autoria e a capacidade escritora do aluno. Para tanto, utilizaremos o sistema retórico aristotélico, as contribuições de Bakhtin (1997) e de Bazerman (2015), bem como as categorias sugeridas 
por Piovezan (2017), para análise de autoria, em um texto produzido na escola.

Para um leigo ou mesmo educadores com pouca experiência, uma produção escrita pode não dizer muito. Mas, sob um olhar atento e com conhecimentos sobre os gêneros textuais e procedimentos de autoria, e apoio do sistema retórico, um professor terá condições de verificar o desempenho de seu aluno tanto no domínio de habilidades textuais quanto discursivas.

Nesse sentido, apresentamos adiante uma breve sequência de atividades que devem comprovar as teorias até aqui desenvolvidas. Para esse fim, foi solicitada a uma turma de alunos de $6^{\circ}$ ano do Ensino Fundamental II de uma escola estadual, localizada em Itapevi (Grande São Paulo), a realização de duas produções de texto: uma totalmente descontextualizada e focada no produto final; e outra contextualizada e com foco no processo produtivo.

A primeira proposta foi apresentada na lousa com a seguinte redação:

\section{Produção de texto 1}

Elabore uma carta a ser dirigida a uma autoridade municipal pedindo providências sobre a falta de coleta de lixo no seu bairro.

Os alunos tiveram pouco mais de dez minutos para concluírem e entregarem suas produções. Como não houve maiores explicações do professor sobre procedimentos e propósitos de escrita, os alunos, repletos de dúvidas, produziram textos que não apresentavam características do gênero carta argumentativa. Não sabiam se se tratava de uma carta de leitor, de solicitação ou familiar, pois não estava claro como a carta deveria ser escrita nem para quem exatamente seria dirigida. Com isso, os estudantes produziram textos incompletos, focados mais no referente "falta de coleta de lixo" do que na argumentação necessária para atingir resultados. Os textos apresentaram também unidade de sentido sofrível, com linguagem informal e estrutura desorganizada.

Já a segunda proposta foi apresentada em folha impressa com as seguintes instruções:

Produção de texto 2

Imagine que você foi convidado(a) a participar de uma reunião com moradores do seu bairro para discutir um problema que atinge a todos há mais de um mês: a falta de coleta de lixo e os problemas decorrentes disso.

Ao final da reunião, você foi escolhido(a) para escrever 
dos moradores e explicando o porquê da urgência em se resolver o problema.

A sua carta precisa ser argumentativa e deverá ter uma linguagem formal e tentar convencer o prefeito para que atenda a reivindicação com urgência. Você pode pesquisar sobre o tema saneamento básico e limpeza pública para reforçar seus argumentos e explicações.

O professor leu a proposta de forma compartilhada, esclareceu dúvidas pontuais e chamou atenção para os termos destacados. Explicou se tratar do gênero carta argumentativa ${ }^{3}$ e que para o texto alcançar seu propósito era preciso pensar em argumentos e exemplos que comovessem e convencessem o destinatário (o prefeito), a resolver o problema (falta de coleta de lixo). Nesse ponto, sugeriu-se que os alunos pesquisassem em casa o tema da limpeza pública e os riscos causados pelo acúmulo de lixo em calçadas e terrenos baldios. $\mathrm{Na}$ aula seguinte, deveriam trazer suas anotações e registros de pesquisa.

Nem todos realizaram a pesquisa, por isso foi solicitado que relacionassem o que soubessem sobre o tema. Antes de iniciarem a produção de texto, o professor apresentou um modelo de carta argumentativa (fictícia), conforme segue:

3 Optamos pelo termo "carta argumentativa", mas como correlata à "carta de solicitação" que, conforme Leal e Brandão, poderia ser utilizada em "qualquer etapa de escolarização, mas os objetivos didáticos e as demandas em relação aos alunos podem mudar radicalmente, sendo necessário, para isso, diagnosticar o que eles já sabem e delimitar o que precisariam saber, considerando o nível de escolaridade em que se encontram" (LEAL e BRANDÃO, 2007, p. 62). 


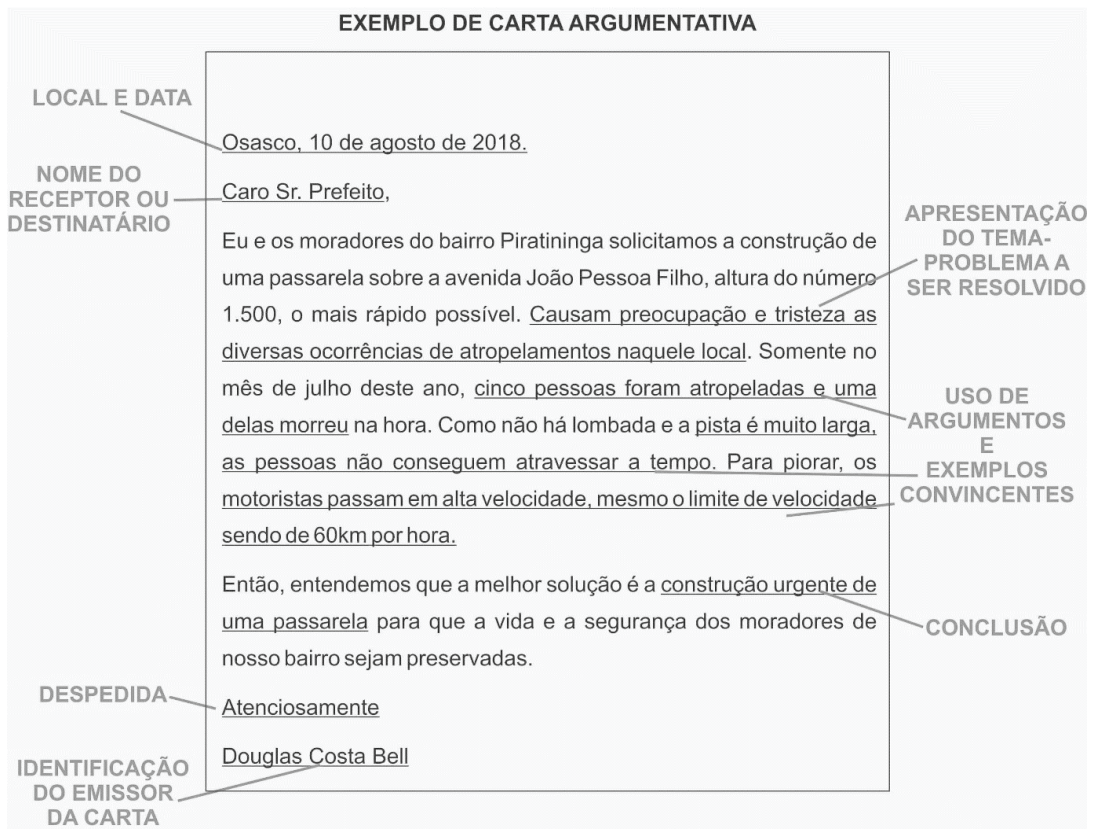

Imagem 1: Modelo de carta argumentativa fictícia com descrição da estrutura.

Após leitura compartilhada do texto acima, os alunos tiveram cerca de dez minutos para produzirem seus textos. Durante a produção, foi possível observar que:

- Os alunos apresentaram maior tranquilidade e certeza em sua produção;

- O propósito tornou-se mais claro, pois conheciam o seu interlocutor;

- Com informações a respeito das consequências do acúmulo de lixo nas ruas, os alunos puderam selecionar e organizar argumentos, com exemplos, comparações e evidências;

- A estrutura do gênero carta argumentativa foi respeitada, conforme modelo apresentado.

- Houve momentos de reflexão sobre o papel e a força da escrita para resolver problemas do cotidiano e da vida social.

- Os alunos ficaram mais satisfeitos com o resultado. 
Para uma verificação mais atenta, selecionamos a carta de uma aluna produzida a partir da proposta de produção de texto 2 :

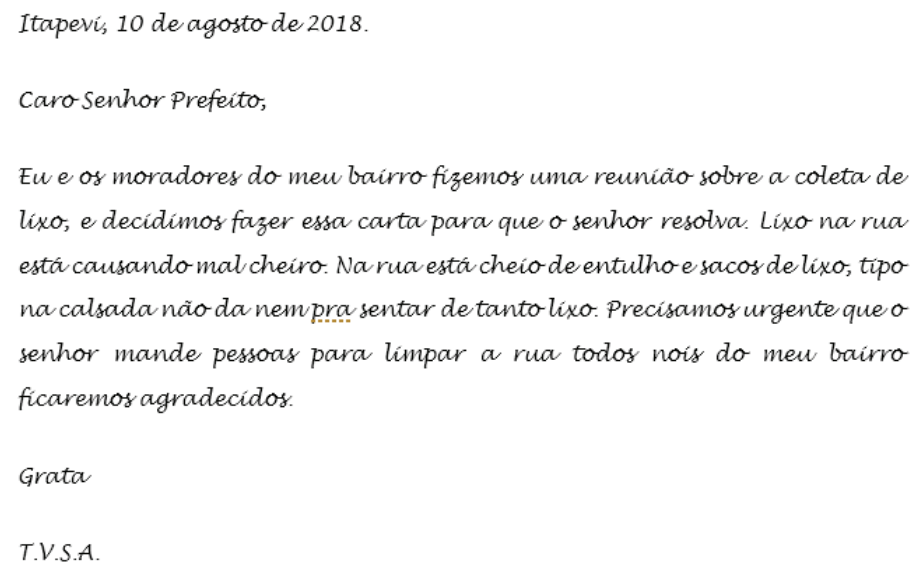

Imagem 2: Transcrição de carta argumentativa produzida por uma aluna de $6^{\circ}$ ano.

\section{Kairós, atos de fala e fato social}

O texto acima foi elaborado (e mantida a escrita original) a partir de uma pequena, mas necessária, reflexão em que o tempo oportuno, kairós, conforme Bazerman (2015), ajuda a perceber a posição do momento adequado para agir e "modificar o curso dos eventos por meio de nossa intervenção oportuna" (BAZERMAN, 2015, p. 59)". Observamos que a aluna-autora assimilou as instruções no tocante à necessidade de intervir para resolver uma questão hipotética, que mobilizou seus vizinhos e amigos.

Há uma exigência (convencer o prefeito) para corrigir uma imperfeição (acúmulo de lixo nas ruas) que precisa ser resolvida. Uma vez imbuído de redigir um texto (ato social) que represente o interesse coletivo para uma causa comum, a aluna-autora lança mão de diversas habilidades linguísticas, textuais e discursivas, ainda que de maneira simples como uma carta que reivindica solução do problema local de uma comunidade.

Nesse momento, a aluna-autora toma consciência da necessidade de 
utilizar estratégias de dizer direcionadas a uma autoridade que possui poder de resolução do problema. A aluna-autora está prestes a criar um fato social a partir de seu ato de fala, que deverá se manifestar pela escrita da carta ao prefeito. Afinal, "atos de fala devem tornar-se fatos sociais ao serem bem-sucedidos" (BAZERMAN, 2015, p. 88).

\section{Sistema retórico}

Analisadas a conjuntura local e a tarefa que lhe foi dada, a aluna-autora teve um momento de reflexão para pensar no que dizer e para quem dizer (invenção). Optou por demonstrar consequências do acúmulo de lixo: mau cheiro, entulho e sacos de lixo amontoados, impedimento da mobilidade urbana. Também propôs uma solução imediata: pessoas para limpar a rua (disposição). Há dois argumentos básicos aqui: um lógico, que apresenta causa e consequência, como o lixo amontoado causa mau cheiro e não permite que se use a calçada; e outro psicológico, que apela para o interlocutor reconhecendo nele uma autoridade e a gratidão dos moradores, ou seja, busca sensibilizar o prefeito por sua benevolência (elocução).

Em sua construção textual, verifica-se que faltou uma revisão gramatical (ação), mas isso não prejudica em nada a intencionalidade expressada pelo conteúdo temático. Nesse aspecto, a disposição e a elocução revelam unidade de sentido e certa qualidade com a distribuição correta dos itens da carta, organização das orações, concordância, coesão e coerência. A autoconsciência de linguagem pode ser verificada no trecho: "na calçada nem dá para sentar de tanto lixo", pois reflete o fato de que os moradores de bairros periféricos, muitas vezes por falta de opções de lazer, costumam ficar sentados na calçada onde conversam, ouvem música, brincam ou passam o tempo.

\section{Gênero textual}

A partir do modelo de carta argumentativa, a aluno-autora, ao contrário da proposta de redação 1, passa a conhecer a forma composicional, o tratamento adequado ao conteúdo temático e começa a desenvolver um estilo de linguagem, refletido na escolha de palavras e na formalidade apropriada para cada caso. Na carta em análise, a aluna-autora atende à estrutura do gênero, apresenta local e data, vocativo identificando o desti- 
natário, tema-problema, argumentos, conclusão, despedida e identificação do emissor. Assume sua posição de autor em primeira pessoa do discurso, com marca de posição de autor, e revela a ação coletiva de seu texto em: "Eu e os moradores do meu bairro", "decidimos fazer", "precisamos urgente" e "todos nós do meu bairro ficaremos agradecidos".

Ressaltamos que o uso de exemplo, para Bazerman (2015) é fundamental para o aluno conhecer as exigências formais e que as seguir bastaria para tornar o texto eficaz, pois quaisquer informações adicionais poderiam confundir o leitor. Mas, também pondera que alguns gêneros "têm a expectativa de novidade, originalidade, pensamento inovador, uma aptidão situacional particular e outras capacidades de inventio mesmo para cumprir com sucesso os pré-requisitos básicos do gênero" (BAZERMAN, 2015, p. 126).

Além disso, polifonia e a criatividade são indícios que dependem do nível de desenvolvimento do aluno e de sua prática de leitura, de escrita e de conhecimento de mundo. $\mathrm{Na}$ carta em análise, é possível perceber a voz dos moradores adultos que sabem bem que um prefeito é a autoridade que "resolve" os problemas da cidade. De forma um pouco atabalhoada, a aluna-autora diz "decidimos fazer essa carta para que o senhor resolva". A falta de um referente anafórico, como "o problema", por exemplo, poderia ser reparada com uma revisão geral do texto, assim como marcas de oralidade ("tipo") e questões gramaticais ("mal cheiro", "calsada" e "nois").

Enfim, a aluna-autora exerceu sua autoria a partir de uma situação hipotética, mas, que por imitar a realidade, coloca-se como um problema a ser resolvido pela ação letrada. Diante do desafio de escrever com propósito bem definido, com procedimentos de autoria e com condições de escrita, a partir de um modelo e explicações sobre o gênero, a carta argumentativa produzida revela um aluno capaz de intervir em seu meio para modificá-lo ou melhorá-lo. Cumpre assim talvez um dos preceitos mais caros a qualquer educador: formar cidadãos críticos e autônomos.

\section{Para finalizar o início de uma conversa inacabada}

O texto, para muitos escritores experientes, nunca está acabado. Sempre queremos modificar algo aqui ou ali, dizer de outro modo ou mesmo excluir parte do que foi dito. Pois bem, no processo de ensino e aprendizagem, o sujeito aprendente, aos poucos, torna-se aluno-autor, responsável 
pelo dizer, com marca de posição de autor e dotado de autoconsciência de linguagem que lhe permite considerar os fatos da realidade; torna-se arquiteto da estrutura de seu próprio texto, com certa qualidade e com unidade de sentido; torna-se, enfim, um negociador de distâncias, uma vez que pode aprender a interagir com os colegas para verificar a eficácia de seu discurso retórico, atento à presença de outras vozes que contribuem para a identificação de polifonia e possibilidades criativas que a escola pode oferecer com certa primazia a partir dessa etapa da vida.

Com essas condições de produção escrita e com procedimentos de autoria bem delimitados, o aluno-autor estaria preparado para derrotar o "medo do papel em branco" (PASSARELLI, 2012) ou o "monstro da escrita" (MAGALHÃES, 2012) e ver-se como aquele que agora tem o que dizer, para quem dizer e como dizer.

Finalmente, o aluno como autor, para além de uma função que possibilita a identificação em meio à dispersão discursiva, como nos explica Foucault (1969), assume responsabilidade pelo dizer, e as implicações dela decorrentes (CHARTIER, 1999), e dizer com conhecimento e qualidade (POSSENTI, 2002). Mas, acima das possibilidades textuais e discursivas que o professor de língua materna pode apresentar ao aluno-autor, está a oportunidade de torná-lo um sujeito atuante em seu meio para melhorá -lo ("modificar sua paisagem"); que consiga identificar o tempo oportuno (kairós) para exercer sua "ação letrada" (BAZERMAN, 2015); que possa se interessar pela vida de sua cidade, de sua pólis; que se expresse com competência, por meio da palavra escrita, da ação letrada, de atos de fala, e crie fatos sociais a partir de textos argumentativos eficazes. 


\section{Referências}

ARISTÓTELES. Retórica. Trad. Edson Bini. São Paulo: Edipro, 2013. de Janeiro: Tecnoprint, s/d. Arte retórica. Trad. Antonio Pinto de Carvalho. 15 ed. Rio BITZER, L. The rethorical situation. Philosophy and Rethoric, 1, 1-14, 1968.

BRASIL. Base Nacional Comum Curricular: Educação é a base. Brasília: MEC, 2017.

CHARTIER, R. A aventura do livro: do leitor ao navegador. Trad. Reginaldo de Moraes. São Paulo: UNESP, 1999.

BAKHTIN, M. Estética da criação verbal. São Paulo: Martins fontes, 1997.

BAZERMAN, C. Retórica da ação letrada. São Paulo: Parábola editorial, 2015.

DOLZ, J; SCHNEWULY, B. Gêneros orais e escritos na escola. Trad. e org. Roxane Rojo e Glais Sales Cordeiro. Campinas, SP: Mercado de Letras, 2004.

FERREIRA, L. A. Retórica e determinação dos sentidos: as perguntas da escola e as respostas da vida. In: MOSCA, L. L. S. Retórica e argumentação em práticas sociais discursivas. Coimbra: Grácio Editor, 2016, p. 141-158.

Contexto, 2010.

. Leitura e persuasão: princípios de análise retórica. São Paulo:

FOUCAULT, M. O que é um autor? França: Bulletin de la Societé Française de Philosophic, 63. ano, n. 3, julho-setembro de 1969, p 73-104. (Societé Française de Philosophie, 22 de fevereiro de 1969; debate com M. de Gandillac, L. Goldmann, J. Lacan, J. d’Ormesson, J. Ullmo, J. Wahl).

LEAL, T. F.; BRANDÃO, A. C. P. É possível ensinar a produzir textos! Os objetivos didáticos e a questão da progressão escolar no ensino da escrita. In

(orgs). Produção de textos na escola: reflexões e práticas no Ensino Fundamental, 1. ed., 1 reimp. Belo Horizonte: Autêntica , 2007.

MAGALHÃES, A. L. O medo na escola: aspectos retóricos e filosóficos. In: ; FERREIRA, L. A. (orgs.). A retórica do medo. São Paulo: Grupo

ERA, 2012.

MOSCA, L. do L. S. Velhas e novas retóricas, convergências e desdobramentos. In:__ (Org.). Retóricas de ontem e de hoje, 3. ed. São Paulo: Associação Editorial Humanitas, 2004, p. 17-54.

PASSARELLI, L. M. G. Ensino e correção na produção de textos escolares. 1 ed. São Paulo: Telos, 2012.

PIOVEZAN, E. S. O lugar do autor na escola. 2017. Dissertação (Mestredo em Língua Portuguesa) - Pontifícia Universidade Católica, São Paulo.

POSSENTI, S. Indícios de autoria. Perspectiva, Florianópolis, vol. 20, n. 1, p. 105-124, jan/jun 2002.

REBOUL, O. Introdução à retórica. Trad. Ivone Castilho Benedetti. São Paulo: Martins Fontes, 2004 (Justiça e Direito)

TRINGALI, D. A retórica antiga e as outras retóricas: a retórica como crítica literária. São Paulo: Musa, 2014. 
